\title{
Discovertebral (Andersson) lesions of the spine in ankylosing spondylitis revisited
}

\author{
Johannes L. Bron • Mirjam K. de Vries • \\ Marieke N. Snieders • \\ Irene E. van der Horst-Bruinsma • Barend J. van Royen
}

Received: 21 October 2008 /Revised: 9 February 2009 /Accepted: 25 February 2009/Published online: 18 March 2009

(C) The Author(s) 2009. This article is published with open access at Springerlink.com

\begin{abstract}
A well-known complication in patients with ankylosing spondylitis (AS) is the development of localised vertebral or discovertebral lesions of the spine, which was first described by Andersson in 1937. Since then, many different terms are used in literature to refer to these localised lesions of the spine, including the eponym 'Andersson lesion' (AL). The use of different terms reflects an ongoing debate on the exact aetiology of the AL. In the current study, we performed an extensive review of the literature in order to align communication on aetiology, diagnosis and management between treating physicians. AL may result from inflammation or (stress-) fractures of the complete ankylosed spine. There is no evidence for an infectious origin. Regardless of the exact aetiology, a final common pathway exists, in which mechanical stresses prevent the lesion from fusion and provoke the development of pseudarthrosis. The diagnosis of AL is established on conventional radiography, but computed tomography and magnetic resonance imaging both provide additional information. There is no indication for a diagnostic biopsy. Surgical instrumentation and fusion is considered the principle management in symptomatic $\mathrm{AL}$ that fails to resolve from a conservative treatment. We advise to use the term Andersson lesion for these spinal lesions in patients with AS.
\end{abstract}

J. L. Bron · M. N. Snieders · B. J. van Royen $(\bowtie)$

Department of Orthopedic Surgery,

VU University Medical Center,

De Boelelaan 1117,

1081 HV Amsterdam, the Netherlands

e-mail: BJ.vanRoyen@vumc.nl

M. K. de Vries • I. E. van der Horst-Bruinsma

Department of Rheumatology, VU University Medical Center,

Amsterdam, the Netherlands
Keywords Andersson lesion · Ankylosing spondylitis · Pseudarthrosis · Spine

\section{Introduction}

Ankylosing spondylitis (AS) is a chronic inflammatory disease that primarily affects the spine and sacroiliac joints, causing pain, stiffness and a progressive thoracolumbar kyphotic deformity [1]. In the late state of the disease, the spine demonstrates progressive ossification of the annulus fibrosis, anterior longitudinal ligament, apophyseal joints, interspinous and flaval ligaments ligament resulting in a complete ankylosed spine, often referred to as a 'bamboo spine' [2]. A well-known complication in these patients is the development of a localised vertebral or discovertebral lesions of the spine, which was first described by Andersson in 1937 [3]. The exact prevalence of discovertebral lesions complicating AS in literature is unknown, but reported prevalences range from $1.5 \%$ to over $28 \%$ [411]. This large variation may be explained by the lack of proper diagnostic criteria and the differences in the extent of spinal survey undertaken. Since the study of Andersson, many different terms have been used to refer to these localised lesions of the spine, including the eponym 'Andersson lesion' (AL), 'discovertebral lesion', 'vertebral lesion', 'destructive vertebral lesion', 'spondylodiscitis', 'discitis', 'diskitis', 'sterile diskitis', 'pseudarthrosis' or '(stress-) fracture' $[4,5,7,10,12-20]$. The use of so many different terms to describe ALs in patients with AS reflects an ongoing debate on the exact aetiology of these spinal lesions. There also seems to be a discrepancy in the terminology used by the specialists treating patients with AS, most often rheumatologists and orthopaedic surgeons. The aim of this study was to perform an extensive review of 
the literature of these lesions, in an effort to align communication on aetiology, diagnosis and management between treating physicians.

\section{Literature search methods}

A comprehensive search was performed for all scientific literature, written in English and published between 1966 and July 2008 referenced on Medline, concerning discovertebral lesions in AS. The following search string was used: ((ankylosing spondylitis OR spondylitis ankylopoietica OR bechterew OR Marie Strumpell disease OR Marie Struempell disease OR Spondyloarthritis OR bamboo spine) AND (Andersson Lesion OR discovertebral lesion OR vertebral lesion OR destructive lesion OR spondylodiscitis OR discitis OR diskitis OR vertebral osteomyelitis OR pseudarthrosis OR fracture)) AND ((Humans[Mesh]) AND (English[lang])). The articles were subsequently screened for opinions on aetiology, diagnosis and management. There are no randomised controlled trials available studying patients with ALs. In the current review, we use the term AL to refer to a localised vertebral or discovertebral lesion complicating AS.

\section{Discussion}

\section{Aetiology}

Since the first report by Andersson [3], several aetiologies for the development of ALs in patients with AS have been postulated, including infection, inflammation, trauma and mechanical stress. Because of the radiographic resemblance with osteomyelitis and spondylodiscitis, an infectious origin has been suggested by some authors, but this has never gained much popularity in literature $[11,21]$. Up to now, only two case reports have been reported that might support an infectious aetiology of the AL $[18,22]$. Lohr et al. described a patient with AS, with a history of intravenous drugs abuse, with a T11-T12 spondylodiscitis and a positive culture of Staphylococcus aureus in the pleural fluid, urine and one of eight blood cultures [18]. The patient was treated by antibiotics, and 6 days later, he underwent a right thoracotomy. Unfortunately, no histology and cultures of the lesion were described after surgery. Nikolaisen et al. described a case with an active inflammatory histological appearance; however, they did not achieve positive cultures by biopsy [22]. Subsequently, biopsies have been performed in patients with an AL in many studies, but positive cultures have never been found and tuberculosis was never detected $[4,6,10,15,21,22]$. Furthermore, sedimentation rates in AS patients are often elevated and usually do not further increase when an ALs develops [4].
In Table 1, the clinical studies, including at least six patients with AL from the past three decades, are summarised. This table demonstrates that most studies either refer to a traumatic/mechanical (pseudarthrosis) or inflammatory (spondylodiscitis) aetiology when describing ALs. Some differences between the studies can be noted; firstly, studies performed by rheumatologists generally refer to spondylodiscitis, whereas orthopaedic surgeons or radiologists always refer to pseudarthrosis. Secondly, when $\mathrm{AL}$ is described as spondylodiscitis, there are multiple lesions in most patients, and these lesions are always (trans) discal. Thirdly, when AL is described as pseudarthrosis, usually, a single lesion is observed. The lesion can be transdiscal or transvertebral and is usually accompanied by fractures or non-fusion of the posterior elements. These differences suggest that the ALs that have been studied by the authors might represent a heterogeneous group of lesions. In 1972, Cawley et al. was the first to divide ALs in two different groups: localised lesions and extensive lesions. Localised lesions occurred early in the course of AS, supporting an inflammatory mechanism. These lesions were further subdivided according to their exact location: the discal surface of the vertebral rim or the cartilaginous part of the vertebral endplate. Extensive lesions involved both locations and were exclusively seen in patients with an ankylosed spine [4]. Based on radiological features a division in five categories has also been proposed: pseudodystrophic, pseudotuberculous, extensive erosions, bone condensation and isolated narrowing of the intervertebral spaces [7]. The first two categories and early erosions should result from an inflammatory process and the remainder and late erosions from mechanical factors. However, none of these theories have become generally accepted.

\section{Inflammation}

AS is characterised by spinal inflammation, and it is therefore not surprising that many authors have focussed on an inflammatory aetiology of ALs. Romanus was the first to describe 'anterior spondylitis', which comprised marginal erosions of the anterior vertebral corners related to inflammation of the anterior annulus fibrosus in patients with AS [23]. The erosion becomes enclosed by a rim of sclerosis and further healing results in the formation of syndesmophytes, finally resulting in a complete ankylosed spinal segment. It has been postulated that AL might be exceptional extensions of this inflammatory process $[4,13$, 23, 24]. Marsh even documented a symptomatic Romanus lesion rontgenologically, which progressed to a complete destructive lesion within 2 years [25]. However, many authors disagree since the Romanus lesion is an enthesitis limited to the junction of the anterior longitudinal ligament and annulus fibrosus [16, 26]. Furthermore, Romanus 
Table 1 Overview of studies with at least six AL patients

\begin{tabular}{|c|c|c|c|c|c|c|c|c|c|c|}
\hline $\begin{array}{l}\text { Author } \\
\text { (year) }\end{array}$ & Affiliation & diagnosis & $\begin{array}{l}N \text { patients } \\
(\% \text { of AS } \\
\text { patients) }\end{array}$ & $\begin{array}{l}N \\
\text { lesions }\end{array}$ & Trauma & $\begin{array}{l}\text { Posterior } \\
\text { elements }\end{array}$ & $\begin{array}{l}\text { (Trans) } \\
\text { discal }\end{array}$ & $\begin{array}{l}\text { Trans } \\
\text { vertebral }\end{array}$ & Symptomatic & Level \\
\hline $\begin{array}{l}\text { Cawley } \\
(1972)\end{array}$ & Reu & $\begin{array}{l}\text { Destructive } \\
\text { lesion }\end{array}$ & $15(-)$ & $>18$ & 4 & $3 \times$ fracture & All & - & $14(93 \%)$ & $\begin{array}{l}>5 \mathrm{~T}, 2 \mathrm{TL} \\
8 \mathrm{~L}\end{array}$ \\
\hline $\begin{array}{l}\text { Modena } \\
(1978)\end{array}$ & Reu & Spondylodiscitis & $9(14 \%)$ & $>22$ & n.k. & n.k. & All & - & n.k. & n.k. \\
\hline Chan (1987) & $\operatorname{Rad}$ & Pseudarthrosis & $18(-)$ & 22 & n.k. & $\begin{array}{l}15 \times \text { fracture } \\
5 \times \text { unfused } f j\end{array}$ & 22 & - & $18(100 \%)$ & $\begin{array}{c}4 \mathrm{~T}, 7 \mathrm{TL} \\
5 \mathrm{~L}\end{array}$ \\
\hline $\begin{array}{l}\text { Wu (1987), } \\
\text { Fang (1988) }\end{array}$ & Ort & Pseudarthrosis & $35(15.9 \%)$ & 40 & 7 & $\begin{array}{l}34 \times \text { fracture } \\
6 \times \text { unfused } f j\end{array}$ & 37 & 3 & $31(89 \%)$ & $\begin{array}{l}13 \mathrm{~T}, 9 \mathrm{TL} \\
18 \mathrm{~L}\end{array}$ \\
\hline Rasker (1996) & Reu & Spondylodiscitis & $6(1.5 \%)$ & 11 & 0 & n.k. & 6 & - & $6(100 \%)$ & $\begin{array}{l}5 \mathrm{~T}, 1 \mathrm{TL}, \\
3 \mathrm{~L}, 2 \mathrm{LS}\end{array}$ \\
\hline $\begin{array}{c}\text { Kabasakal } \\
\text { (1996) }\end{array}$ & Reu & Spondylodiscitis & $12(8 \%)$ & 32 & 0 & 0 & 32 & - & $2(17 \%)$ & $\begin{array}{l}6 \mathrm{~T}, 4 \mathrm{TL}, \\
21 \mathrm{~L}, 1 \mathrm{LS}\end{array}$ \\
\hline Shih (2001) & $\operatorname{Rad}$ & $\begin{array}{l}\text { Fractures or } \\
\text { pseudarthrosis }\end{array}$ & $16(-)$ & 16 & 12 & $16 \times$ fracture & 12 & 4 & $16(100 \%)$ & $\begin{array}{l}1 \mathrm{C}, 8 \mathrm{~T}, 3 \mathrm{TL}, \\
4 \mathrm{~L}\end{array}$ \\
\hline $\begin{array}{c}\text { Langlois } \\
\text { (2005) }\end{array}$ & Reu & Aseptic discitis & $14(18 \%)$ & 16 & 1 & n.k. & 16 & - & $12(86 \%)$ & $\begin{array}{c}1 \mathrm{C}, 5 \mathrm{~T}, 3 \mathrm{TL}, \\
6 \mathrm{~L}, 1 \mathrm{LS}\end{array}$ \\
\hline Chan (2006) & Ort & Pseudarthrosis & $30(-)$ & 30 & 30 & $30 \times$ fracture & 30 & - & $30(100 \%)$ & $\begin{array}{l}\text { All between : } \\
\text { T9 and L3 }\end{array}$ \\
\hline Kim (2007) & Ort & Pseudarthrosis & $12(-)$ & 19 & 4 & n.k. & 19 & - & $7(58 \%)$ & $\begin{array}{r}10 \mathrm{~T}, 1 \mathrm{TL} \\
7 \mathrm{~L}, 1 \mathrm{LS}\end{array}$ \\
\hline
\end{tabular}

$n . k$. not known, $f j$ facet joints, $C$ cervical, $T$ thoracal, $T L$ thoracolumbar, $L$ lumbar, $L S$ lumbosacral

lesions usually affect multiple levels and ALs often involves only a single level, indicating that at least additional factors should be involved [7]. The localised lesions in the vertebral rim described by Cawley et al. [5] seem to include Romanus lesions, and this might also be the case in other studies. A different theory, for the lesions that mainly involve the vertebral endplates of the intervertebral disc, is the herniation of nucleus material through the endplates [27]. This process could be stimulated by vertebral osteoporosis, which is a well-known feature early in the course of AS. Moreover, apophysal joint disease could attribute to the herniation process by increasing forces across the discovertebral junction and stimulating breaks in the endplates and subchondral bone [27]. The nucleus pulposus is an avascularised tissue, and contact with the vascularised subchondral bone is suspected to provoke a serious inflammatory response [28]. However, there is no evidence thus far to support this hypothesis. A theory that has become more widely accepted combines the inflammatory process with its mechanical effects on the spine. During the course of the disease, the extent of spinal inflammation and spinal fusion is not equally distributed over all vertebral or discovertebral segments. Local areas with increased spinal inflammation and decreased spinal fusion permit an excessive degree of mobility, resulting in a local non-union of the ankylosed spine [10, 17].

ALs show variable results on histological examination (Table 2) [15]. Generally, aspecific reactive changes are found with the intervertebral disc being replaced by hypovascular fibrous tissue. The endplates show irregular destruction, extending into the subchondral bone. Fragments of necrotic bone and cartilage are often found across the vertebral border. Mild inflammatory changes may also be present, with infiltration of plasma cells, lymphocytes or, less often, macrophages. Although this infiltration could be a secondary feature, Nikolaisen et al. revealed infiltration with plasma cells $(\mathrm{Ig} \mathrm{A}+)$ and lymphocytes $(\mathrm{CD} 3+)$ in specimens taken in the early course [22]. Later biopsies in the same patients only showed reactive changes with bone formation. According to the authors, these findings support a primary inflammatory origin for ALs [22]. Further histological evidence favouring an inflammatory origin is sparse, but several hypotheses have been postulated. Additional factors favouring an inflammatory origin of ALs include the occurrence of lesions early in the stage of AS, before the spine has become completely ankylosed, and the occurrence of multiple lesions within a patient, of asymptomatic lesions and absence of a history of trauma in many patients.

\section{Trauma}

In many patients, the AL develops after trauma and is associated with a fracture of the spine. The ankylosed and osteoporotic spine in AS patients is prone for fracturing due to loss of spinal mobility [29-34]. The bone mineral density in AS patients is often decreased, and approximately half of 
Table 2 Overview of the histological appearances of tissue obtained from ALs reported over the past 20 years

\begin{tabular}{|c|c|c|c|c|}
\hline Author (year) & Tissue retrieval & Samples & Description & Diagnosis \\
\hline $\begin{array}{l}\text { Fang (1988) and } \\
\text { Wu (1987) }\end{array}$ & Surgical resection & 18 & $\begin{array}{l}\text { Fibrous tissue with a poorly vascularised central zone containing irregular bundles of } \\
\text { collagen fibres and aggregates of blood vessels. Irregular destruction of endplates } \\
\text { extending into subchondral bone. Fragments of necrotic bone and cartilage across } \\
\text { vertebral border. Inflammatory cells generally absent }\end{array}$ & PA \\
\hline Arnold (1989) & Surgical resection & 1 & Fibrocartilage with low grade inflammatory infiltrate and necrotic bone fragments & DL \\
\hline Peh (1993) & Surgical resection & 1 & $\begin{array}{l}\text { Vascularised fibrous tissue and organising fibrinous exudate adjacent to fragments of } \\
\text { bone and cartilage }\end{array}$ & $\mathrm{PA}$ \\
\hline Rasker (1996) & Open biopsy & 2 & $\begin{array}{l}\text { Aspecific reactive changes infiltration of lymphocytes, plasma cells and scarce } \\
\text { macrophages and destruction of bone }\end{array}$ & SD \\
\hline $\operatorname{Lim}(1996)$ & Open biopsy & 1 & Scanty inflammatory infiltrates & $\mathrm{SD}$ \\
\hline Petterson (1996) & $\begin{array}{l}\text { Open biopsy (1); } \\
\quad \text { fine needle (1) }\end{array}$ & 2 & Non-specific chronic inflammation and degenerative changes & PA \\
\hline $\begin{array}{l}\text { Nikolaisen } \\
\text { (2005) }\end{array}$ & $\begin{array}{l}\text { Fine needle } \\
\text { aspiration }\end{array}$ & 1 & $\begin{array}{l}\text { Dense collagenous tissue diffusely infiltrated by regular plasma cells and } \\
\text { lymphocytes }(\mathrm{CD} 3+)\end{array}$ & $\mathrm{SD}$ \\
\hline Langlois (2005) & Open biopsy & 3 & Tissue repair, no evidence of inflammation & $\mathrm{D}$ \\
\hline Kim (2007) & Surgical resection & 19 & $\begin{array}{l}\text { Hypovascular fibrous tissue with fibrinoid necrosis and chondrodysplasia. Irregular } \\
\text { destruction of endplates with sclerotic bony spincules. Fragments of necrotic bone } \\
\text { and cartilage within the degenerated fibrotic marrow }\end{array}$ & $\mathrm{PA}$ \\
\hline
\end{tabular}

$P A$ pseudarthrosis, $D L$ destructive lesion, $S D$ spondylodiscitis, $D$ discitis

the patient population can be classified as osteoporotic. This is especially the case in the older patients or patients with long-standing disease. The fractures may occur after a direct trauma or due to chronic mechanical stress.

Acute fractures in AS are most commonly observed near the thoracolumbar junction [35]. Especially, in a long ankylosed thoracolumbar kyphothic spinal column, local stresses near the thoracolumbar junction are increased dramatically. Fracturing of the ankylosed spine in AS results in a fracture of both the anterior and posterior part of the vertebral column and may pass through the vertebrae (transvertebral) or more commonly through the calcified disc region (transdiscal) [36]. A transvertebral spinal fracture leads to spinal instability, comparable to a flexion distraction fracture or Chance fracture of the vertebral body and the fused posterior facet joints [10, 35, 37]. Traumatic fractures of the cervical spine, however, are also common in patients with AS, but the development of an AL is less frequently observed at this location [30,38]. An explanation could be the less severe mechanical loading in the cervical spine compared to the lower spine.

Repeated stress itself may also lead to a fracture of the ankylosed spine, comparable with a stress fracture in long bones $[9,10,39]$. Beside the thoracolumbar junctions, areas that suffer from increased stresses are the levels proximal to the lumbosacral junction, where conditions like disc degeneration and sponylolisthesis occur in the non-rigid spine. Stress fractures may also occur initially in the posterior column prior to the appearance of an anterior discovertebral lesion [10]. The thoracolumbar and lumbar spine have disc spaces most susceptible to shearing or distraction under the effect of gravity in the kyphotic spine.
Bone is more susceptible to distraction than to compressive forces. Especially during hyperflexion loads, the posterior elements experience large tension forces and may fail initially [35]. A relation between the occurrence of ALs and heavy manual labour has been reported [5, 7]. In addition, cases have been described of patients who developed a symptomatic AL after improvement of their mobility due to anti-inflammatory treatment or total hip arthroplasty [40, 41].

In the complete ankylosed spine, a (stress-) fracture will be the only moving segment between the long lever arms. This is similar to the 'last mobile segment' principle as described earlier and is therefore sometimes referred to as a 'final common pathway' $[6,10]$. Persistent motion at the fracture site may hinder fracture healing and union, resulting in a sclerotic unfused spinal segment. Such a sclerotic spinal lesion can be compared with a hypertrophic pseudarthrosis of a long bone $[5,6,10,12,16,42-45]$.

\section{Pseudarthrosis}

In an attempt to summarise the available data on aetiology, three different groups may be recognised: (1) localised lesions that always have an inflammatory origin. (2) Extensive lesions without fractured posterior elements. These lesions result from a combination of inflammatory and mechanical factors (last mobile segment) and are always transdiscal and associated with unfused facet joints. (3) Extensive lesions with fractured posterior elements resulting from mechanical factors ((stress-) fracture) and may be located transdiscal or transvertebral. Lesions from groups 2 and 3 have a final common pathway and will both result in pseudarthrosis with the typical appearance of the 
AL (Fig. 1). It might be questioned whether the first group of lesions should be considered as ALs since these lesions have a different aetiology, different mechanical consequences and may require different management.

History and clinical presentation

Patients with an AL are most commonly middle-aged males (63-86\%), known with longstanding AS [7, 45, 46]. However, ALs may occur at any level and during every course of the disease. Cases of patients in whom the $\mathrm{AL}$ was the initial sign of AS have been reported [17]. The occurrence of an AL has also been described in an 11-year-old female patient [47]. The main complaint is progressive localised thoracolumbar pain or sharp localised pain preceded by a (minor) trauma [5, 9, 48]. Patients may also be asymptomatic, and the $\mathrm{AL}$ is discovered with routine radiological evaluation of the spine. Sometimes, patients may be unaware or already have forgotten a preceding trauma $[7,49]$. Occasionally, radiculopathy and neurogenic intermittent claudication due to nerve root or myelum compression may be the presenting symptom [50]. The symptoms are aggravated by verticalisation and relieved by lying flat. Clinical investigation may reveal percussion tenderness on the affected spinal level [51]. A thoracolumbar kyphosis is often present and may show progression during follow-up. Kauppi stated: "If a bamboo spine starts to bend, something is wrong". In some patients, multiple lesions may be present or develop simultaneously, which can make diagnosis more difficult. Fever is not a sign of AL and should raise the suspicion for other potential conditions, such as infections. Kabasakal et al. tried to score the severity of the lesion on an empirical 0 10 scale, in which 1 is defined as suspicious change and 10 represents the end stage of the AL [11]. However, this scoring system has not been followed in literature.

\section{Radiography}

Conventional radiographs are the initial imaging study of choice. Plain radiographs are most reliable to determine the exact level of the lesion when the lowest rib is included in the image. Especially in AS patient presenting with localised pain after a trauma, a high index of suspicion is required [49]. Finkelstein et al. showed that a significant part of the spinal fractures is initially missed, allowing progression to pseudarthrosis [12]. The AL is revealed by osteolytic destruction with a surrounding zone of reactive sclerosis and vertebral osteophytes [9]. The spinal lesion
Fig. 1 Schematic presentation of the development of discovertebral (Andersson) lesions; lesions may originate from inflammation combined with unfused segments (last mobile segment; $a$ ), fractures trough the ankylosed disc $(b)$ or fractures trough the vertebral body $(c)$. Finally, a characteristic Andersson lesion develops, with (e) or without $(d)$ a kyphotic deformity

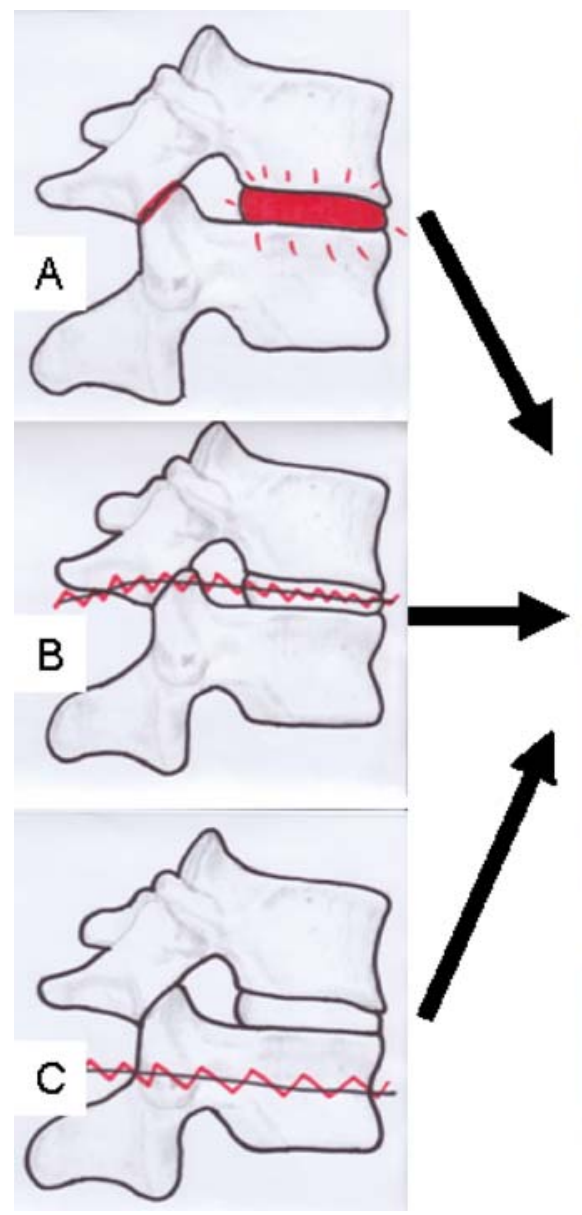


can be confined to the vertebral body (transvertebral), through the disc space (transdiscal), or both (discovertebral) [36]. In transdiscal lesions, the disc space is conspicuously more radiolucent than its neighbour disc spaces which are fused. The lesions may be accompanied by fractures of the posterior elements, which generally can be exposed by lateral radiographs. An intervertebral vacuum phenomenon may be visible at the side of the lesion, and the disc space can be increased or narrowed. Angular kyphosis with or without spondylolisthesis in the $\mathrm{AL}$ is a regular prominent feature. In cases with a severe global thoracolumbar kyphotic deformity, the apex of the kyphosis is most often at the level of the AL (Figs. 2a and 3a). Flexion and extension radiographs may show motion in some cases. These radiological features are not pathognomonic for ALs and may also be seen in septic spondylitis or spondylodiscitis. Dihlmann et al. state that AL can be differentiated radiologically from an inflammatory spondylodiscitis by the demonstration of a circumscribed defect in one or two neighbouring vertebral bodies with varying degrees of narrowing of the intervening disc space, angular kyphosis of the affected spinal segment and an area of reactive sclerosis in the vertebral cancellous bone surrounding the defect [24].

\section{Computed tomography imaging}

Computed tomography (CT) imaging is superior to conventional radiographs in determining the extent of the lesion (Fig. 2b). CT imaging of an AL shows irregular vertebral or discovertebral osteolysis with surrounding reactive sclerosis [52]. CT can always accurately demonstrate
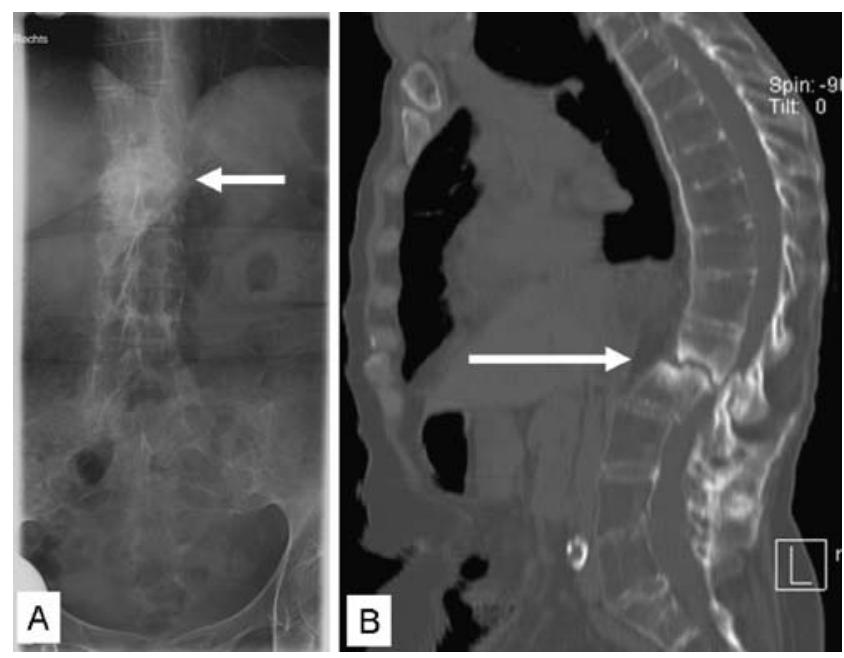

Fig. 2 Anteroposterior plain radiograph from an AL at the thoracolumbar junction in a 56-year-old female AS patient (a). A sagittal reconstructed CT image of the same patient shows central osteolysis surrounded by an irregular sclerotic zone (b). The lesion extends into the posterior elements and has resulted in narrowing of the spinal canal

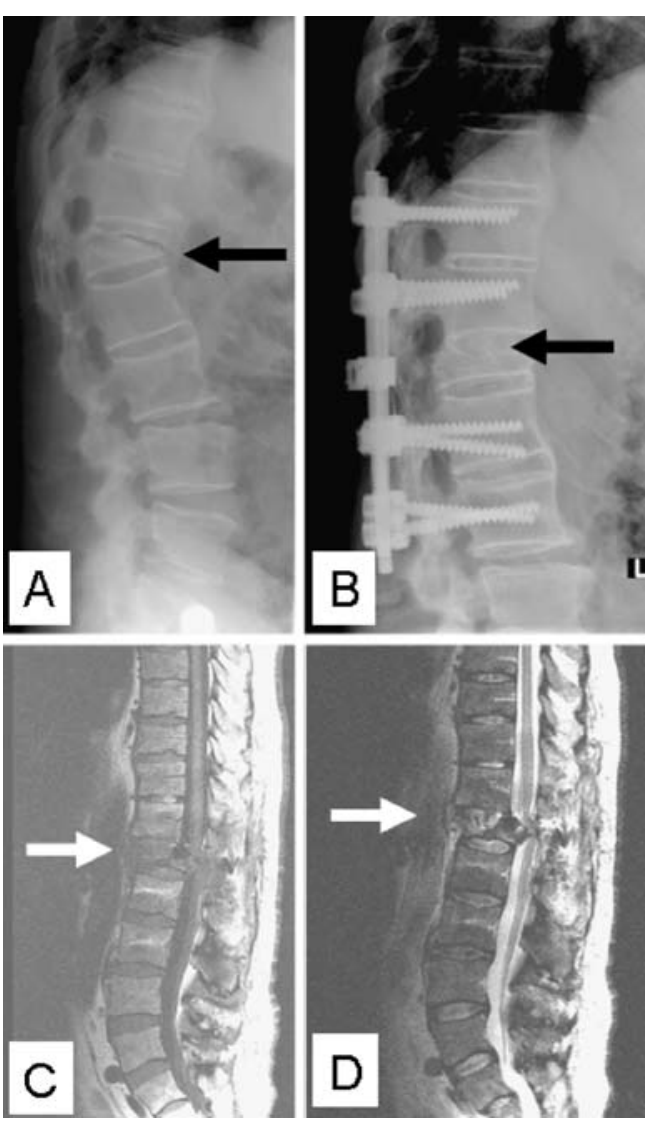

Fig. 3 Lateral plain radiograph with a kyphotic discovertebral AL at the thoracolumbar junction in a 60-year-old male AS patient (a). Radiograph after posterior instrumentation and fusion of the symptomatic AL is also shown (b). T1- (c) and T2-weighted (d) sagittal MR images accurately reveal involvement of the surrounding structures. The lesion has resulted in a severely narrowed spinal canal, with dural compression, that clinically resulted in a postoperative partial peroneal nerve palsy of his right leg

fractures of the posterior elements or non-fusion of the facet joints. In addition to conventional plain radiographs, CT imaging is more sensitive in demonstrating vacuum phenomena and paraspinal swellings. The transversal imaging is used to determine the presence, location, severity and nature of spinal stenosis. Chan et al. described 18 AS patients with 22 spinal pseudarthrosis, who underwent conventional radiography as well as CT imaging. In $77 \%$ of the lesions, CT imaging provided data that were missed on conventional radiography. Therefore, CT offers considerable contributory advantages over conventional radiography in diagnosing AL complicating AS [52]. However, CT scanning had the disadvantage of irradiation, which should be considered when choosing the appropriate imaging method.

Magnetic resonance imaging

Magnetic resonance imaging (MRI) is considered the best modality in visualising AL with the highest sensitivity [13, 
39, 53]. Generally, reduced signal intensity of the disc space and surrounding vertebral bodies and increased signal intensity after enhancement with contrast medium is noticeable on T1-weighted images (Figs. 3c and 4a). On T2-weighted images, increased signal intensity in the corresponding area is noticeable (Figs. $3 \mathrm{~d}$ and $4 \mathrm{~b}$ ). In addition, contrast-enhanced fat suppression imaging allows a better differentiation between fat and enhanced lesions. Considering a diagnosed $\mathrm{AL}$ of the spine in $\mathrm{AS}$ on plain radiographs and CT images, MR images can supplement information on anterior longitudinal ligament disruption, vertebral translation, abnormal dural enhancement, epidural lesions and spinal canal stenosis [39]. In addition, MRI is advised to evaluate spinal canal encroachment and the extent of changes in the dura, spinal cord, nerve roots, soft tissue and ligaments $[13,39,53]$. A decreased spinal canal can be observed caused by anterior and posterior extradural tissue resulting from hypertrophic ligamentum flavum and facet joints, as well as from hypertrophic callus formation of the anterior and posterior elements of the AL. Differentiation from infectious spondylitis and primary or metastatic tumours of the spine is possible if criteria such as morphology, extension of bone marrow oedema, contrast enhancement and signal intensity in the disc space on T2weighted and fat suppression sequence are taken in consideration $[53,54]$.

\section{Bone scintigraphy}

The use of both early and late bone scintigraphy can be used to identify AL complicating AS and to differentiate the lesion from infection. However, the literature, which describe the use of bone scintigraphy in patients with AS complicated by AL, is only scarce $[8,16,46]$. Focal areas of increased isotope retention in the late state of AS may identify the AL. In a prospective study of 63 patients with AS, Lentle et al. found evidence of a sterile diskitis in five patients [8]. Two of them were not recognised on radiographs and bone scintigraphy led to the diagnosis. Park et al. described 16 patients with a 'spinal pseudarthrosis' complicating AS [46]. The spinal lesion was confirmed with bone scintigraphy in all 16 patients. However, Arnold et al. described a case with an $\mathrm{AL}$ in longstanding $\mathrm{AS}$ in which bone scintigraphy did not demonstrate an increased uptake [16].

\section{Laboratory tests}

The role of laboratory tests in patient with an AL is limited. Both erythrocytes sedimentation rate and C-reactive protein levels may be elevated in patients with ALs, but this is of little diagnostic value $[5,7,10,22,47]$. Both parameters are usually more associated with the involvement of peripheral joints [55]. White blood count and blood cultures are of no additional diagnostic value.

\section{Histology}

There is no indication for a biopsy in patients with AS suspected from an AL. However, tissue for histological examination might be obtained when surgical treatment is performed. The lesions have variable histological appearances discussed earlier (Table 2).

\section{Management}

Conservative treatment is often the first step of treatment, but there are no trials available showing its optimal duration. Spontaneous relief of symptoms up to 3 years of conservative management has been reported, and the strategy should be adjusted to each individual patient. In the upper thoracic spine, the presence of an intact sternalrib complex provides stability and might prevent kyphosis, which was recently described as 'the fourth column' [56]. At the more mobile cervical and thoracolumbar levels, however, conservative management is less efficient. Stabilisation can be obtained by plaster immobilisation or Halo-jacket
Fig. 4 T1-weighted sagittal MRI of a 47-year-old AS patients showing an $\mathrm{AL}$ at the L1-L2 level with characteristically reduced signal intensity. T2-weighted images reveal a central destructive zone surrounded by an area with reduced signal intensity at both sides
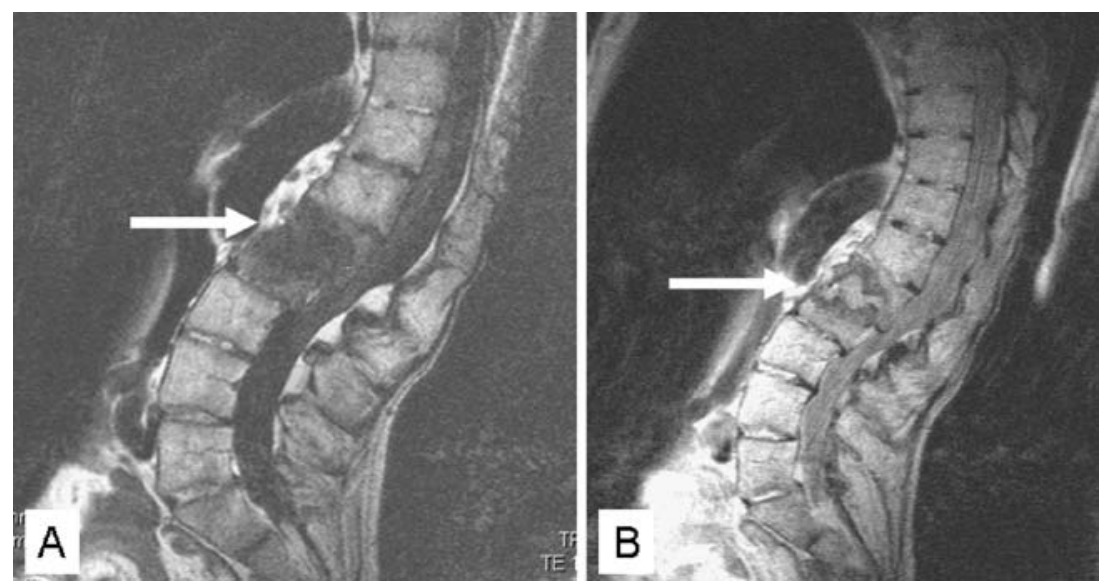
immobilisation. Despite a normal bone-healing capacity in AS patients, fusion of an extensive AL by plaster immobilisation is not likely $[5,10]$. Even with long-term plaster immobilisation using a thoracolumbosacral orthosis with one hip included, minimal persistent motion at the AL may hinder fracture healing and union. Although plaster immobilisation or Halo-jacket immobilisation has been reported as a success in the treatment of acute fractures in AS [29], there is no evidence suggesting successful recovery of AL in AS patients after a long time of immobilisation treatment. However, correction of a progressive cervical kyphotic deformity resulting from a cervical fracture can be achieved by immediate halo-jacket immobilisation followed by (gradual) correction by manipulation.

The use of non-steroidal anti-inflammatory drugs during the active phases of the disease forms the mainstay of the pharmacological management of AS. Newer therapies that have been introduced, including anti-tumour necrosis factor$\alpha$ therapy with infliximab, etanercept and adalimumab. There is no evidence that treatment with these drugs is also beneficial in the treatment of symptomatic AL. A rigorous exercise programme, as advocated in the treatment of AS, is contraindicated in patients with AL complicating AS [41].

\section{Surgery}

Surgical treatment is indicated in patients with unbearable pain, progression of the symptoms, a progressive kyphotic deformity or neurological deficits. Surgical decompression, stabilisation and fusion form the mainstay of the surgical management of AL complicating AS (Fig. 3b). The goal is both to decompress the spinal canal and to restore spinal stability facilitating healing and fusion of the spinal lesion. Numerous surgical techniques have been advocated, including instrumented and non-instrumented stabilisation through anterior, posterior or combined approach [57]. The surgical procedure depends on the localisation of the lesion, alignment of the spine, neurological deficit and the location of thecal sac compression $[5,10,39]$. In patients with a (progressive) thoracolumbar kyphotic deformity, posterior correction and fixation of the AL by an anterior opening wedge osteotomy [45] or a posterior transpedicular wedge resection osteotomy [58] may be considered.

\section{Conclusions}

In an attempt to structure the broad spectrum of Andersson lesions complicating AS, a provisory division in localised and extensive lesions can be used. Localised lesions are limited to certain parts of the intervertebral disc and always have an inflammatory origin. Extensive lesions affect the whole disc or vertebral body and may result from both mechanical and inflammatory factors. Aetiologies range from spinal (stress-) fractures to a local delay in the ankylosing process compared to adjacent levels, resulting in the last mobile segment. Regardless of the exact aetiology, mechanical factors in the ankylosed spine will prevent healing of extensive lesions and promote the formation of pseudarthrosis. Initially, plain radiographs should be performed. MRI scanning might be used for further evaluation, and in selected cases, CT scanning can be performed. At this time, bone scanning does not have a place in the analysis of Andersson lesions in AS. There is no consensus in literature regarding the management of these lesions and when surgical intervention should be performed. The mainstay of surgical treatment, however, consists of instrumentation and fusion, with the correction of a kyphotic deformity, when present. Since radiological appearance, mechanical consequences, prognosis and management in extensive lesions differ from localised lesions, it may be questioned whether the latter should be classified as Andersson lesions. The eponym Andersson lesion should be preserved to extensive lesions, which is actually a spinal pseudarthrosis and the final common pathway of several different aetiologies.

\section{Disclosures None.}

Authorship criteria and contributions All listed authors approved the final version of the manuscript. All authors affirmed that they have met all three of the criteria for authorship.

Open Access This article is distributed under the terms of the Creative Commons Attribution Noncommercial License which permits any noncommercial use, distribution, and reproduction in any medium, provided the original author(s) and source are credited.

\section{References}

1. Von Bechterew W (1893) Steifigkeit der wirbelsäule und ihre Verkrümmung als besondere Erkrankungsform. Neurologisches Zentralblatt 12:426-434

2. McGonagle D, Lyn Tan A, Wakefield R, Emery P (2006) Imaging in ankylosing spondylitis. In: Van Royen BJ, Dijkmans B (eds) Ankylosing spondylitis - diagnosis and management. Taylor \& Francis group, New york, pp 71-81

3. Andersson O (1937) Röntgenbilden vid spondylarthritis ankylopoetica. Nord Med Tidskr 14:2000-2002

4. Rasker JJ, Prevo RL, Lanting PJ (1996) Spondylodiscitis in ankylosing spondylitis, inflammation or trauma? A description of six cases. Scand J Rheumatol 25(1):52-57

5. Cawley MI, Chalmers TM, Kellgren JH, Ball J (1972) Destructive lesions of vertebral bodies in ankylosing spondylitis. Ann Rheum Dis $31(5): 345-358$

6. Wu PC, Fang D, Ho EK, Leong JC (1988) The pathogenesis of extensive discovertebral destruction in ankylosing spondylitis. Clin Orthop 230:154-161 
7. Langlois S, Cedoz JP, Lohse A, Toussirot E, Wendling D (2005) Aseptic discitis in patients with ankylosing spondylitis: a retrospective study of 14 cases. Jt Bone Spine 72(3):248-253

8. Lentle BC, Russell AS, Percy JS, Jackson FI (1977) Scintigraphic findings in ankylosing spondylitis. J Nucl Med 18(6):524-528

9. Chan FL, Ho EK, Fang D, Hsu LC, Leong JC, Ngan H (1987) Spinal pseudarthrosis in ankylosing spondylitis. Acta Radiol 28(4):383-388

10. Fang D, Leong JC, Ho EK, Chan FL, Chow SP (1988) Spinal pseudarthrosis in ankylosing spondylitis. Clinicopathological correlation and the results of anterior spinal fusion. J Bone Joint Surg Br 70(3):443-447

11. Kabasakal Y, Garret SL, Calin A (1996) The epidemiology of spondylodiscitis in ankylosing spondylitis-a controlled study. Br J Rheumatol 35(7):660-663

12. Finkelstein JA, Chapman JR, Mirza S (1999) Occult vertebral fractures in ankylosing spondylitis. Spinal Cord 37(6):444-447

13. Kenny JB, Hughes PL, Whitehouse GH (1990) Discovertebral destruction in ankylosing spondylitis: the role of computed tomography and magnetic resonance imaging. Br J Radiol 63(750):448-455

14. Kurugoglu S, Mihmanli I, Kanberoglu K, Kanberoglu A (2001) Destructive diskovertebral lesions in ankylosing spondylitis: appearance on magnetic resonance imaging. South Med J 94(8):837-841

15. Agarwal AK, Reidbord HE, Kraus DR, Eisenbeis CH Jr (1990) Variable histopathology of discovertebral lesion (spondylodiscitis) of ankylosing spondylitis. Clin Exp Rheumatol 8(1):67-69

16. Arnold MH, Brooks PM, Ryan M, Francis H (1989) A destructive discovertebral lesion: septic discitis, ankylosing spondylitis, or rheumatoid arthritis? Clin Rheumatol 8(2):277-281

17. Bourqui M, Gerster JC (1985) Ankylosing spondylitis presenting as spondylodiscitis. Clin Rheumatol 4(4):458-464

18. Lohr KM, Barthelemy CR, Schwab JP, Haasler GB (1987) Septic spondylodiscitis in ankylosing spondylitis. J Rheumatol 14(3): 616-620

19. Wise CM, Irby WR (1983) Spondylodiscitis in ankylosing spondylitis: variable presentations. J Rheumatol 10(6):1004-1006

20. Adler CP (1985) Spondylitis-spondylodiscitis. Pathologicoanatomical morphology and diagnostic problems. Radiologe 25 (7):291-298

21. Eschelman DJ, Beers GJ, Naimark A, Yablon I (1991) Pseudoarthrosis in ankylosing spondylitis mimicking infectious diskitis: MR appearance. Am J Neuroradiol 12(6):1113-1114

22. Nikolaisen C, Nossent H (2005) Early histology in ankylosing spondylitis related spondylodiscitis supports its inflammatory origin. Scand J Rheumatol 34(5):396-398

23. Romanus R, Yden S (1952) Destructive and ossifying spondylitic changes in rheumatoid ankylosing spondylitis (pelvo-spondylitis ossificans). Acta Orthop Scand 22(2):88-99

24. Dihlmann W, Delling G (1978) Disco-vertebral destructive lesions (so-called Andersson lesions) associated with ankylosing spondylitis. Skeletal Radiol 3:10-16

25. Marsh CH (1985) Internal fixation for stress fractures of the ankylosed spine. J R Soc Med 78(5):377-379

26. Frank P, Gleeson JA (1975) Destructive vertebral lesions in ankylosing spondylitis. Br J Radiol 48(573):755-758

27. Calin A, Robertson D (1991) Spondylodiscitis and pseudarthrosis in a patient with enteropathic spondyloarthropathy. Ann Rheum Dis 50(2):117-119

28. Albert HB, Kjaer P, Jensen TS, Sorensen JS, Bendix T, Manniche C (2008) Modic changes, possible causes and relation to low back pain. Med Hypotheses 70(2):361-368

29. Hitchon PW, From AM, Brenton MD, Glaser JA, Torner JC (2002) Fractures of the thoracolumbar spine complicating ankylosing spondylitis. J Neurosurg Spine 97(2):218-222

30. Hunter T, Dubo HI (1983) Spinal fractures complicating ankylosing spondylitis. A long-term followup study. Arthritis Rheum 26 (6):751-759
31. Mullaji AB, Upadhyay SS, Ho EK (1994) Bone mineral density in ankylosing spondylitis. DEXA comparison of control subjects with mild and advanced cases. J Bone Joint Surg Br 76(4):660-665

32. Olerud C, Frost A, Bring J (1996) Spinal fractures in patients with ankylosing spondylitis. Eur Spine J 5(1):51-55

33. Geusens P, Vosse D, van der Linden LS (2007) Osteoporosis and vertebral fractures in ankylosing spondylitis. Curr Opin Rheumatol 19(4):335-339

34. Cooper C, Carbone L, Michet CJ, Atkinson EJ, O'Fallon WM, Melton LJIII (1994) Fracture risk in patients with ankylosing spondylitis: a population based study. J Rheumatol 21(10):18771882

35. Gelman MI, Umber JS (1978) Fractures of the thoracolumbar spine in ankylosing spondylitis. AJR Am J Roentgenol 130 (3): $485-491$

36. Thorngren KG, Liedberg E, Aspelin P (1981) Fractures of the thoracic and lumbar spine in ankylosing spondylitis. Arch Orthop Trauma Surg 98(2):101-107

37. Chance GQ (1948) Note on a type of flexion fracture of the spine. Br J Radiol 21:452-453

38. Mountney J, Murphy AJ, Fowler JL (2005) Lessons learned from cervical pseudoarthrosis in ankylosing spondylitis. Eur Spine J 14 (7):689-693

39. Shih TT, Chen PQ, Li YW, Hsu CY (2001) Spinal fractures and pseudoarthrosis complicating ankylosing spondylitis: MRI manifestation and clinical significance. J Comput Assist Tomogr 25 (2): $164-170$

40. Mahesh BH, Jayaswal A, Bhan S (2008) Fracture dislocation of the spine after total hip arthroplasty in a patient with ankylosing spondylitis with early pseudoarthrosis. Spine J 8 (3):529-533

41. Sakaura H, Hosono N, Mukai Y, Fujii R, Yoshikawa H (2006) Paraparesis due to exacerbation of preexisting spinal pseudoarthrosis following infliximab therapy for advanced ankylosing spondylitis. Spine J 6(3):325-329

42. Deburge A, Guigui P, Ouahes M, Barre E (1996) Cervical pseudarthrosis in ankylosing spondylitis. A case report. Spine 21 (23):2801-2805

43. Bergmann EW (1949) Fractures of the ankylosed spine. J Bone Joint Surg 31A:669-671

44. Kewalramani LS, Taylor RG, Albrand OW (1975) Cervical spine injury in patients with ankylosing spondylitis. J Trauma 15 (10):931-934

45. Chang KW, Tu MY, Huang HH, Chen HC, Chen YY, Lin CC (2006) Posterior correction and fixation without anterior fusion for pseudoarthrosis with kyphotic deformity in ankylosing spondylitis. Spine 31(13):E408-E413

46. Park WM, Spencer DG, McCall IW, Ward J, Buchanan WW, Stephens WH (1981) The detection of spinal pseudarthrosis in ankylosing spondylitis. Br J Radiol 54(642):467-472

47. Unsal E, Arici AM, Kavukcu S, Pirnar T (2002) Andersson lesion: spondylitis erosiva in adolescents. Two cases and review of the literature. Pediatr Radiol 32(3):183-187

48. Dunn N, Preston B, Jones KL (1985) Unexplained acute backache in longstanding ankylosing spondylitis. Br Med J (Clin Res Ed) 291(6509):1632-1634

49. Hunter T, Forster B, Dvorak M (1995) Ankylosed spines are prone to fracture. Can Fam Physician 41:1213-1216

50. Jobanputra P, Kirkham B, Duke O, Crockard A, Panayi GS (1988) Discovertebral destruction in ankylosing spondylitis complicated by spinal cord compression. Ann Rheum Dis 47 (4):344-347

51. Chang KW, Chen YY, Lin CC, Hsu HL, Pai KC (2005) Closing wedge osteotomy versus opening wedge osteotomy in ankylosing spondylitis with thoracolumbar kyphotic deformity. Spine 30 (14):1584-1593 
52. Chan Ho EK, Chau EM (1988) Spinal pseudarthrosis complicating ankylosing spondylits: comparison of CT and conventional tomography. Am J Roentgenol 150(3):611-614

53. Obradov M, Schonfeld DH, Franssen MJ, de Rooy DJ (2001) Andersson lesion in ankylosing spondylitis. JBR -BTR 84 (2):71

54. Jevtic V (2001) Magnetic resonance imaging appearances of different discovertebral lesions. Eur Radiol 11(7):1123-1135

55. Ozgocmen S, Godekmerdan A, Ozkurt-Zengin F (2007) Acutephase response, clinical measures and disease activity in ankylosing spondylitis. Joint Bone Spine 74(3):249-253
56. Shen FH, Samartzis D (2007) Successful nonoperative treatment of a three-column thoracic fracture in a patient with ankylosing spondylitis: existence and clinical significance of the fourth column of the spine. Spine 32(15):E423-E427

57. Fox MW, Onofrio BM, Kilgore JE (1993) Neurological complications of ankylosing spondylitis. J Neurosurg 78 (6):871-878

58. Van Royen BJ, Kastelijns RC, Noske DP, Oner FC, Smit TH (2006) Transpedicular wedge resection osteotomy for the treatment of a kyphotic Andersson lesion complicating ankylosing spondylitis. Eur Spine J 15(2):246-252 